\title{
Soft drink consumption linked with fatty liver in the absence of traditional risk factors
}

\author{
Nimer Assy $M D^{1,2}$, Gattas Nasser $M D^{3}$, lad Kamayse $M D^{4}$, William Nseir $M D^{5}$, \\ Zaza Beniashvili $M D^{1}$, Agness Djibre $M D^{1}$, Maria Grosovski PhD ${ }^{6}$
}

\begin{abstract}
N Assy, G Nasser, I Kamayse, et al. Soft drink consumption linked with fatty liver in the absence of traditional risk factors. Can J Gastroenterol 2008;22(10):811-816.
\end{abstract}

BACKGROUND: Little is known about dietary habits and their relationships with liver disease in nonalcoholic fatty liver disease (NAFLD) patients, particularly in the absence of obesity, diabetes or hyperlipidemia.

OBJECTIVE: To assess the association between soft drink consumption and the presence of fatty liver in NAFLD patients who do not have classic risk factors.

METHODS: Three hundred ten patients with NAFLD diagnosed by ultrasound were assessed for 36 months in a cross-sectional manner. Thirty-one patients (10\%) who had NAFLD without classic risk factors were compared with 30 healthy controls. Physical activity was assessed during the preceding week and year, and every six months for 36 months. Data on daily dietary intake of food and soft drink, and the source of added sugar were collected during two seven-day periods, at the beginning of the study, and within two weeks after the metabolic tests by using a validated food questionnaire given by a trained dietician. Insulin resistance and lipid peroxidation were assessed by homeostasis model assessment-insulin resistance index (HOMA-IRI) and malondialdehyde (MDA) levels, respectively.

RESULTS: Eighty per cent of patients (25 of 31) consumed an excessive amount of soft drink beverages (more than $50 \mathrm{~g} /$ day of added sugar) for 36 months, compared with $20 \%$ in healthy controls $(\mathrm{P}<0.001)$. Twenty per cent of patients consumed one drink per day, $40 \%$ consumed two to three drinks per day, and $40 \%$ consumed more than four drinks per day for most days during 36 months. The most common soft drinks consumed were regular Coca-Cola (40\% of patients), Diet Coke (40\%) and flavoured fruit juices (20\%). Ultrasound findings revealed mild fatty liver in $44 \%$ of cases $(\mathrm{n}=14)$, moderate fatty liver in $38 \%(\mathrm{n}=12)$, and severe fatty liver in $18 \%(n=5)$. HOMA-IRI and MDA levels were significantly higher in patients with NAFLD than in healthy controls (HOMAIRI, 3.7 versus $1.7, \mathrm{P}<0.001$; and $\mathrm{MDA}, 420 \pm 300 \mu \mathrm{mol} / \mathrm{mL}$ versus $200 \pm 100 \mu \mathrm{mol} / \mathrm{mL} ; \mathrm{P}<0.001)$. When controlled for other factors, including dietary composition and physical activity, soft drink beverage consumption was the only independent variable that was able to predict the presence of fatty liver in $82.5 \%$ of cases with a sensitivity of $100 \%$, a specificity of $76 \%$, a positive predictive value of $57 \%$ and a negative predictive value of $100 \%$.

CONCLUSION: The present study may add important insight into the role of sugar-sweetened beverage consumption as a cause of fatty liver in patients without risk factors. Patients are encouraged to change their long-standing drinking behaviour.

Key Words: Fatty liver; Fructose; Soft drink; Steatohepatitis

\section{La consommation de boissons gazeuses reliée à la stéatose hépatique simple en l'absence de facteurs de risques classiques}

HISTORIQUE : On ne sait pas grand-chose du lien entre les habitudes alimentaires et les maladies hépatiques chez les patients atteints de stéatose hépatique non alcoolique (SHNA), notamment en l'absence d'obésité, de diabète ou d'hyperlipidémie.

OBJECTIF : Évaluer l'association entre la consommation de boissons gazeuses et la présence de stéatose hépatique simple chez les patients atteints de SHNA qui ne présentent pas de facteurs de risque classiques. MÉTHODOLOGIE : Trois cent dix patients atteints de SHNA diagnostiquée par échographie ont subi une évaluation transversale pendant 36 mois. Les auteurs ont comparé 31 patients (10\%) atteints de SHNA sans facteurs de risque classiques à 30 sujets en santé. Ils ont évalué leur activité physique au cours de la semaine et de l'année précédentes, puis tous les six mois pendant 36 mois. Ils ont colligé les données sur l'apport diététique quotidien d'aliments et de boissons gazeuses ainsi que les sources de sucre ajouté pendant deux périodes de sept jours, au début de l'étude et dans les deux semaines suivant les tests métaboliques, au moyen d'un questionnaire validé sur l'alimentation, présenté par une diététiste formée. Ils ont évalué la résistance à l'insuline et la peroxydation lipidique par évaluation du modèle d'homéostasie - indice de résistance à l'insuline (HOMA-IRI) et les taux de malondialdéhyde (MDA), respectivement. RÉSULTATS : Quatre-vingts pour cent des patients (25 des 31) consommaient trop de boissons gazeuses (plus de $50 \mathrm{~g} / \mathrm{jour}$ de sucre ajouté) pendant 36 mois, par rapport à $20 \%$ des sujets en santé. ( $\mathrm{P}<0,001)$. Vingt pour cent des patients consommaient une boisson gazeuse par jour, $40 \%$ en consommaient deux à trois par jour et $40 \%$, plus de quatre par jour la plupart des jours pendant 36 mois. Les boissons gazeuses les plus consommées étaient le Coca-Cola régulier ( $40 \%$ des patients), le Coke diète $(40 \%)$ et les boissons à saveur de fruits (20\%). L'échographie a révélé une stéatose hépatique légère dans $44 \%$ des cas $(n=14)$, une stéatose hépatique modérée dans $38 \%$ des cas $(\mathrm{n}=12)$ et une stéatose hépatique grave dans $18 \%$ des cas $(\mathrm{n}=5)$. L'HOMA-IRI et les taux de MDA étaient considérablement plus élevés chez les patients atteints de SHNA que chez les témoins en santé (HOMA-IRI de 3,7 par rapport 1,7, $\mathrm{P}<0,001$; et MDA de $420 \pm 300 \mu \mathrm{mol} / \mathrm{mL}$ par rapport à $200 \pm 100 \mu \mathrm{mol} / \mathrm{mL} ; \mathrm{P}<0,001)$. Lorsqu'ils étaient contrôlés pour d'autres facteurs, y compris la composition diététique et l'activité physique, la consommation de boissons gazeuses était la seule variable indépendante capable de prévoir la présence de stéatose hépatique simple dans $82,5 \%$ des cas avec une sensibilité de $100 \%$, une spécificité de $76 \%$, une valeur prédictive positive de $57 \%$ et une valeur prédictive négative de $100 \%$

CONCLUSION : La présente étude peut donner un aperçu important du rôle de la consommation de boissons édulcorées au sucre comme cause de stéatose hépatique simple chez les patients sans facteurs de risque. Les patients sont invités à modifier leur comportement de longue date en matière de consommation de boissons.

${ }^{1}$ Liver Unit, Ziv Medical Center, Safed; ${ }^{2}$ Rappaport Faculty of Medicine, Technion - Israel Institute of Technology, Haifa; ${ }^{3}$ Department of Internal Medicine, Western Galilee Hospital, Nahariya; ${ }^{4}$ Liver Unit, Rambam Medical Center, Haifa; ${ }^{5}$ Department of Internal Medicine,

Holy Family Hospital, Nazareth; ${ }^{6}$ Department of Biotechnology, ORT Braude College, Karmiel, Israel

Correspondence: Dr Nimer Assy, Liver Unit, Ziv Medical Center, PO Box 1008, Safed 13100, Israel. Telephone 9-724-682-8441,

fax9-724-682-8442, e-mail assy.n@ziv.health.gov.il or assy.nimer@gmail.com

Received for publication February 13, 2008. Accepted June 4, 2008 
$\mathrm{N}$ ormally, less than $5 \%$ of the liver is fat by weight, but in patients with nonalcoholic steatohepatitis (NASH), as much as $50 \%$ to $80 \%$ of liver weight may be made up of fat, mostly in the form of triglycerides (1). The clinical implications of NASH are derived mostly from its common occurrence in the general population (10\% to $24 \%$ ) and its potential to progress to fibrosis (30\% to $40 \%)$, cirrhosis $(20 \%$ to $30 \%)$ and hepatocellular carcinoma $(2,3)$. NASH is the most common cause of cryptogenic cirrhosis and is an increasingly common indication for liver transplantation (3). Nonalcoholic fatty liver disease (NAFLD) is one of the most important emerging health care issues, and obesity, type 2 diabetes mellitus and hyperlipidemia are conditions frequently associated with NAFLD $(1,2)$. However, patients without traditional risk factors have also been reported to have fatty infiltration of the liver (3). Identifying new risk factors that permit early diagnosis and treatment are warranted. Soft drinks are the leading cause of added sugar in the diet worldwide. Recent evidence suggests that sugar-sweetened soft drink consumption is associated with the risk of obesity and diabetes because they contain large amounts of high-fructose corn syrup (HFCS), which raises blood glucose similarly to sucrose (4). In addition, soft drinks contain caramel colouring, which is rich in advanced glycation end products that might increase insulin resistance and inflammation (4-6).

The intake of nutrients (including sweetened beverages) may affect insulin resistance, carbohydrate and lipid metabolism, and hepatic steatosis, yet many other factors may actually play a role (4). However, there are few published reports on the intake of various nutrients in patients with NAFLD. Recently, it has been reported that patients with fatty liver consume more simple carbohydrates and less saturated fat than those in the general population, suggesting that imbalanced diets play important roles in the development and progression of NAFLD, and that correction of these diets may be necessary (7).

High-fructose diets have induced fatty liver in rats and ducks (8). Such diets have also caused increases in hepatic lipid peroxidation and activation of inflammatory pathways in the liver of rats (9). Fructose consumption can cause progressive liver disease in humans, which is demonstrated by the inborn error of metabolism known as hereditary fructose intolerance. Aldolase $\mathrm{B}$ is a rare disease that results from a deficiency of the fructose metabolizing enzyme (10). The extent to which excessive fructose might contribute to the high prevalence of NAFLD in western societies has not been systematically investigated. More recently, soft drink consumption has been linked with obesity and has been shown to increase the risk of the metabolic syndrome. Individuals consuming more than one soft drink per day had a higher prevalence of the metabolic syndrome than those consuming less than one drink per day. Whether soft drink consumption is linked with NAFLD has not been assessed (11). The aim of the present study was to assess the association between soft drink consumption and the presence of fatty liver by comparing NAFLD patients with no classic risk factors with age-matched, healthy controls.

\section{METHODS}

Three hundred ten patients with NAFLD, as diagnosed by ultrasound, were referred to the liver unit and assessed during a 36-month recruitment period in a cross-sectional manner. Ten per cent of patients $(n=31)$ had NAFLD with no obvious classic risk factors (ie, diabetes, obesity, hyperlipidemia and hypertension). These outpatients sought medical advice for abdominal discomfort, hepatomegaly and/or abnormal liver enzymes. Patients reporting the consumption of alcohol (more than $140 \mathrm{~g} /$ week, or more than $20 \mathrm{~g} /$ day in women and $30 \mathrm{~g} /$ day in men), use of drugs (tamoxifen, steroids, amiodarone) and the presence of other risk factors that may induce hepatic steatosis (hepatitis $\mathrm{C}$ virus or hepatitis B virus infection), as well as patients with autoantibodies indicative of autoimmune hepatitis or celiac disease were excluded. A similar age- and sexmatched, healthy control group $(n=30)$ with normal ultrasounds (same operator) and normal liver enzyme levels, and without diabetes, obesity or hyperlipidemia was randomly selected from the general population (teachers at the local Catholic secondary school [Fassouta, Israe]) were identified randomly and matched by the principal investigator). The healthy control group denied excessive alcohol intake (mean of $70 \mathrm{~g} /$ week to $80 \mathrm{~g} /$ week). Excessive soft drink beverage consumption was defined as more than $50 \mathrm{~g} /$ day of added sugar (11). Using a validated questionnaire, in-person interviews were conducted by a trained and experienced dietician to collect data regarding dietary habits, physical activity and other relevant information (12). The 1998 version of the Block food frequency questionnaire is the most frequently used questionnaire for metabolic and dietary intervention studies and has been used in mixed-sex and multiethnic populations. It is a validated, self-administered questionnaire with pictures of standardized serving sizes to estimate the usual dietary intake. Daily average food and beverage intake was recorded twice (two seven-day records; one at the beginning of the study and one within two weeks after the metabolic tests). Intake categories included breads, pizza and savoury snacks; pasta, rice and corn; potatoes, peas and beans; milk and dairy products; juices and soft drinks; nuts, and fresh and dried fruits; sugar, sweets, cakes and chocolate; and fresh vegetables. Physical activity was assessed by the well-validated Paffenbarger questionnaire (13). The time frame included activity during the preceding week and year, and every six months for 36 months. Light activity (5 kcal/min) included walking, gardening, dancing and ice skating. Moderate activity $(10 \mathrm{kcal} / \mathrm{min})$ included swimming, running, jogging, basketball and football. Combination activity $(7.6 \mathrm{kcal} / \mathrm{min})$ included weight lifting. Subjects with alcohol abuse were excluded by interviewing patients and their relatives. Alcohol consumption was assessed using a validated questionnaire (14). Each patient was asked how many times per week he or she usually drank alcohol, as well as the usual amount consumed. They were asked to estimate the amount in terms of the size of popular Israeli cups $(60 \mathrm{~mL})$ or a bottle of beer. The information obtained also included the style of drinking, type of alcohol consumed, average and maximum amount drank each time, and life events that have affected drinking pattern. Based on this information, the amount of alcohol consumed per week was calculated. Lipid determinations, and liver enzyme, glucose and insulin levels were determined by standard biochemical methods. Insulin resistance was estimated using the oral glucose tolerance test-derived homeostasis model assessment-insulin resistance index (HOMA-IRI), derived from the following equation:

Insulin resistance $=$ fasting plasma glucose level $(\mathrm{mg} / \mathrm{dL}) \times$

$0.055 \mathrm{mmol} / \mathrm{L} \times$ fasting plasma insulin level $(\mu \mathrm{g} / \mathrm{L}) / 22.5$

A patient was considered to be obese if the calculated body mass index exceeded $28 \mathrm{~kg} / \mathrm{m}^{2}$. They were determined to 
have diabetes if fasting plasma glucose levels were higher than $6.3 \mathrm{mmol} / \mathrm{L}$, which is two times the upper limit of normal. Metabolic syndrome was defined as the presence of three or more of the following: waist circumference $88.9 \mathrm{~cm}$ or more (women), or $101.6 \mathrm{~cm}$ or more (men); fasting blood glucose $5 \mathrm{mmol} / \mathrm{L}$ or higher; serum triglycerides $1.5 \mathrm{mmol} / \mathrm{L}$ or higher; blood pressure 135/85 $\mathrm{mmHg}$ or higher; and highdensity lipoprotein cholesterol lower than $1 \mathrm{mmol} / \mathrm{L}$ (men) or lower than $1.25 \mathrm{mmol} / \mathrm{L}$ (women) (11). As markers of lipid peroxidation, the levels of malondialdehyde (MDA) in plasma were evaluated using commercial kits (LPO; Oxis International Inc, USA). Ultrasound examinations were performed within two weeks of presentation. Each examination was performed using a real-time, high-resolution Acuson grey scale/colour ultrasound scanner (Acuson Diagnostic, USA). The examinations were performed by a single experienced sonographer who was blinded to the clinical status of the patients. The combination of brightness and liver-kidney contrast with two other well-known ultrasound findings of fatty liver - vascular blurring and deep attenuation - allowed for the diagnosis and grading of fatty change to be determined semiquantitatively. Three degrees of fatty infiltration were described: mild, for a minimal diffuse increase in hepatic echogenicity, and normal visualization of the diaphragm and intrahepatic vessel borders; moderate, for a moderate diffuse increase in hepatic echogenicity, and slightly impaired visualization of intrahepatic vessels and the diaphragm; and severe, for a marked increase in echogenicity, poor penetration of the posterior segment of the right lobe, and poor or no visualization of the hepatic vessels and diaphragm (15). During followup, a second ultrasound examination was performed six months after the complete discontinuation of soft drink consumption. Metabolic measures, physical activity and dietary information were retrieved by the validated food questionnaire. The study was approved by the Ziv Medical Center's internal review board (Safed, Isreal), and all patients signed informed consent for participation.

\section{Statistics}

Data are expressed as the mean \pm SD. Differences between two variables were assessed by Wilcoxon's signed rank test, the univariate $\chi^{2}$ test and a $t$ test, when appropriate. Correlations were assessed using Spearman's rho test and univariate regression analysis. The diagnostic validity of single or combined variables (source of added sugar, total energy intake, carbohydrate intake, physical activity, alcohol consumption, and ferritin, MDA and HOMA-IRI values) were tested regarding the correct classification of fatty liver versus healthy controls. The percentages of cases correctly classified by each index, and the sensitivity, specificity, positive predictive value and negative predictive value were determined by discriminant analysis.

\section{RESULTS}

Table 1 shows the demographic, clinical and metabolic characteristics of the patient population. The mean age of the patients was $30 \pm 13$ years. Fifty-three per cent $(n=16)$ were male. A total of 19 patients $(60 \%)$ had elevated liver enzyme levels. The most common enzyme abnormalities were an elevated serum alanine aminotransferase level in 16 NAFLD patients $(50 \%$; $49 \pm 20 \mathrm{U} / \mathrm{L}$ in NAFLD versus $23 \pm 11 \mathrm{U} / \mathrm{L}$ in controls) and
TABLE 1

\begin{tabular}{|c|c|c|c|}
\hline Variable & NAFLD $(n=31)$ & Controls $(n=30)$ & $\mathbf{P}$ \\
\hline $\mathrm{BMI}, \mathrm{kg} / \mathrm{m}^{2}$, mean $\pm \mathrm{SD}$ & $25.6 \pm 2.6$ & $24.9 \pm 2.5$ & 0.3 \\
\hline \multicolumn{4}{|l|}{ Alanine aminotransferase } \\
\hline $\mathrm{U} / \mathrm{L}$, mean $\pm \mathrm{SD}$ & $49 \pm 20$ & $23 \pm 11$ & 0.03 \\
\hline Abnormal levels, $\%$ & 50 & - & \\
\hline \multicolumn{4}{|c|}{ Gamma-glutamyl transpeptidase } \\
\hline $\mathrm{U} / \mathrm{L}$, mean $\pm \mathrm{SD}$ & $44 \pm 25$ & $25 \pm 10$ & 0.02 \\
\hline Abnormal levels, $\%$ & 40 & - & \\
\hline \multicolumn{4}{|l|}{ Glucose, mmol/L } \\
\hline Mean \pm SD & $4.7 \pm 0.4$ & $4.2 \pm 0.6$ & 0.02 \\
\hline Range & $3.3-5.4$ & $3.5-4.5$ & \\
\hline \multicolumn{4}{|l|}{ Fasting insulin, pmol/L } \\
\hline Mean \pm SD & $114.7 \pm 28.6$ & $71.7 \pm 20$ & 0.01 \\
\hline Range & $78.9-143$ & $50-93$ & \\
\hline HOMA-IRI, median (range) & $3.7(2-5)$ & $1.7(1-2)$ & 0.001 \\
\hline \multicolumn{4}{|l|}{ Triglycerides, $\mathrm{mmol} / \mathrm{L}$} \\
\hline Mean \pm SD & $1.1 \pm 0.4$ & $1.08 \pm 0.34$ & 0.06 \\
\hline Range & $0.58-1.5$ & $0.7-1.4$ & \\
\hline \multicolumn{4}{|l|}{ Ferritin, $\mu \mathrm{g} / \mathrm{L}$} \\
\hline Mean \pm SD & $160 \pm 70$ & $130 \pm 80$ & 0.09 \\
\hline Range & $80-200$ & $60-210$ & \\
\hline \multicolumn{4}{|l|}{ Malondialdehyde, $\mu \mathrm{mol} / \mathrm{mL}$} \\
\hline Mean \pm SD & $420 \pm 300$ & $200 \pm 100$ & 0.001 \\
\hline Range & $120-450$ & $100-300$ & \\
\hline
\end{tabular}

Homeostasis model assessment-insulin resistance index (HOMA-IRI) greater than 2 indicates insulin resistance). BMI Body mass index

gamma-glutamyl transpeptidase in 12 NAFLD patients $(40 \%$; $44 \pm 25 \mathrm{U} / \mathrm{L}$ in NAFLD versus $25 \pm 10 \mathrm{U} / \mathrm{L}$ in controls). Ultrasound findings revealed diffuse fatty liver in all patients, of which $44 \%$ of cases $(n=14)$ were mild, $38 \%(n=12)$ were moderate and $18 \%(n=5)$ were severe (16). A significant correlation was found between the amount of soft drink consumed and the extent of fatty infiltration $(r=0.63 ; \mathrm{P}<0.001)$, whereas no relationships were observed with other food constituents. HOMA-IRI and MDA levels were significantly higher in patients with NAFLD than in healthy controls without NAFLD (HOMA-IRI, 3.7 versus 1.7, respectively, $\mathrm{P}<0.001$; and MDA, $420 \pm 300 \mu \mathrm{mol} / \mathrm{mL}$ versus $200 \pm 100 \mu \mathrm{mol} / \mathrm{mL}$, respectively, $\mathrm{P}<0.001)$. The normal MDA level is less than $300 \mu \mathrm{mol} / \mathrm{mL}$. After 36 months of follow-up, 12 of 31 patients (39\%) who completely discontinued the consumption of sweetened beverages (after intensive nutritional counselling) for six months showed normal liver appearance on repeated ultrasound. The liver ultrasound fat category was mild in eight patients and moderate in four patients before discontinuation of sweetened beverage consumption.

Table 2 shows the dietary constituents in NAFLD patients and controls, and the source of added sugar during one week. Eighty per cent of patients with fatty liver (25 of 31) consumed an excessive amount of soft drink beverages (more than 50 g/day of added sugar) (Coca-Cola, Fanta and Sprite [The Coca-Cola Company, Canada]) and/or flavoured fruit juices (orange, raspberry, 'sport' and mixed) for a period of 36 months, compared with $20 \%$ in healthy controls 


\begin{tabular}{|c|c|c|c|}
\hline Dietary constituents & $\begin{array}{l}\text { NAFLD } \\
(n=31)\end{array}$ & $\begin{array}{c}\text { Controls } \\
(n=30)\end{array}$ & $\mathbf{P}$ \\
\hline $\begin{array}{l}\text { Prevalence of excessive soft drink } \\
\text { consumption (>50 g/day of added sugar), \% }\end{array}$ & $\%$ & 20 & 0.001 \\
\hline Added sugar consumed, g/day & $75.6 \pm 8.4$ & $33.6 \pm 12.6$ & 0.001 \\
\hline \multicolumn{4}{|l|}{ Source of added sugar* } \\
\hline Soft drink and juice & 43 & 8 & 0.001 \\
\hline Sweetened grains (cookies, cakes) & 19 & 18 & 0.5 \\
\hline Sweets and candy (ice cream, chocolate) & 17 & 16 & 0.9 \\
\hline Milk and dairy products & 9 & 20 & 0.03 \\
\hline Other ${ }^{\dagger}$ & 12 & 38 & 0.01 \\
\hline Total energy intake, kcal, mean \pm SD & $2300 \pm 500$ & $2220 \pm 600$ & 0.3 \\
\hline Fat, $\%$ of energy, mean \pm SD & $33 \pm 7$ & $32 \pm 5$ & 0.5 \\
\hline Carbohydrate, $\%$ of energy, mean \pm SD & $49 \pm 7$ & $47.8 \pm 6$ & 0.4 \\
\hline Protein, $\%$ of energy, mean \pm SD & $16 \pm 2$ & $15 \pm 2$ & 0.1 \\
\hline Carbohydrate intake, g/day, mean \pm SD & $340 \pm 85$ & $337 \pm 75$ & 0.6 \\
\hline Physical activity & Light & Light & 0.1 \\
\hline Alcohol, g/day, mean \pm SD & $10 \pm 3$ & $11 \pm 2$ & 0.8 \\
\hline
\end{tabular}

*Presented as per cent contribution to dietary carbohydrate from different sources of added sugar (the recommended upper limit for a $2200 \mathrm{kcal}$ diet is $50 \mathrm{~g} /$ day); ${ }^{\dagger}$ Cereals, other beverages (tea, coffee), fresh vegetables, fresh and dried fruit (1 tsp of sugar $=4.2 \mathrm{~g}$ of sugar)

$(\mathrm{P}<0.001)$. The most common soft drinks consumed were regular Coca-Cola sweetened with $55 \%$ free fructose $(40 \%$ of patients), Diet Coke (The Coca-Cola Company) sweetened with aspartame (40\% of patients) and flavoured fruit juices coloured with caramel (orange, raspberry, 'sport' and energy drinks; $20 \%$ of patients). Twenty per cent of patients consumed one drink per day, $40 \%$ of patients consumed two to three drinks per day and $40 \%$ consumed more than four drinks per day on most days during 36 months. Patients with moderate to severe fatty infiltration were drinking mostly regular Coca-Cola and Diet Coke.

When discriminative analyses and the validity of independent variables were used to make the correct diagnosis of fatty liver, only the 'soft drink consumption' variable was able to classify the results correctly in $82.5 \%$ of cases, whereas sweetened grains, sweets and candy, milk and dairy products, other dietary constituents, alcohol consumption, ferritin, body mass index, HOMA-IRI, and MDA levels were not predictive of the presence of fatty liver. The sensitivity, specificity, positive predictive value and negative predictive value were $100 \%, 76 \%, 57 \%$ and $100 \%$, respectively $\left(\chi^{2}=13 ; P=0.001\right)$. The association between the ingredients in soft drinks (regular Coca-Cola or Diet Coke) and the presence of fatty liver was not analyzed because of the small patient population.

\section{DISCUSSION}

The present study compared dietary constituents, physical activity and liver ultrasound in patients with fatty liver. We found that NAFLD patients without classic risk factors consume more soft drinks and juices than healthy controls. The follow-up data, the correlation between severity of fatty liver and amount of soft drink consumption, and the fact that soft drink consumption was the only independent predictor of fatty liver support the association between soft drink consumption and fatty liver. As expected, insulin resistance (HOMA-IRI) and MDA levels were higher in the group with fatty liver. However, when controlled for other factors, soft drink beverage consumption was the only independent variable that correctly predicted the presence of fatty liver.

The underlying mechanism for this association remains unknown. Soft drink consumption is the leading cause of added sugar in the diet ( 1 tsp of sugar contains $4.2 \mathrm{~g}$ ) (17). Individuals who consume an excessive amount of soft drinks tend to lead a sedentary lifestyle and eat a higher calorie diet (an additional $150 \mathrm{kcal} /$ day to $300 \mathrm{kcal} /$ day) that includes more fructose (18). Because both regular Coca-Cola and Diet Coke consumption in our study resulted in an increased risk of fatty liver, factors other than calories and sugar content likely contribute to the higher risk. These factors include the consumption of fructose, aspartame, caramel (food colourant) and other covariants. These complexes of sugars and colourants may promote insulin resistance, lipid peroxidation and hepatic inflammation, and are a source of glycation end products $(5,19,20)$. The extent to which excessive fructose, aspartame and caramel consumption might contribute to the high prevalence of liver disease in western societies and to the progression of NAFLD to NASH has not been investigated. One study of lean women found that four days of overfeeding with sucrose (glucose plus fructose) drink increased de novo lipogenesis by $200 \%$ to $300 \%$ (21). Another feeding study showed that two days of a high-fructose diet (30\% of the total energy consumed per day, consumed as a sweetened beverage at every meal) resulted in decreased postprandial glucose concentration and insulin response, and prolonged alimentary lipemia in women (22). Another follow-up study indicated that both surplus calories and excessive sucrose consumption play a role in the rise of liver enzyme levels (23). Additional evidence that fructose can cause steatohepatitis is that intravenous administration of fructose to healthy volunteers has resulted in a $75 \%$ decrease in hepatic ATP within 10 min because the liver was overwhelmed and could not metabolize it (24). Fructose can also increase triglyceride levels, de novo synthesis of fatty acids, hyperuricemia and insulin resistance (25). The triglyceride response to fructose ingestion appears to depend on whether a person is carbohydrate-sensitive or insulin-resistant (26). Fructose, especially high-fructose corn syrup, is now used extensively in carbonated beverages and other sweetened drinks, baked goods, candies, canned fruits, sodas, jams, jellies and dairy products (27).

After absorption in the small bowel, fructose is transported via the portal vein to the liver, where it is metabolized by fructokinase to fructose-1-phosphate. This molecule is cleaved by aldolase to form glycerone phosphate and glyceraldehyde-3-phosphate, both of which can be further metabolized in the glycolytic pathway (28). An increase in serum triglycerides and, ultimately, increased low-density lipoprotein cholesterol concentration may result from enhanced fatty acid synthesis, increased esterification of fatty acids and increased very low-density lipoprotein secretion (28). A soft drink containing $32.6 \mathrm{~g}$ of fructose could increase the fasting serum fructose fourfold. A $340 \mathrm{~g}$ soft drink sweetened with fructose-55 contains approximately $40 \mathrm{~g}$ of the sweetener (ie, $22 \mathrm{~g}$ of fructose and $17 \mathrm{~g}$ of glucose, representing a fructose excess of $5 \mathrm{~g}$ per can) $(20,29)$. Fructose affects each of the three major factors that are believed to contribute to the 
pathogenesis of diabetic end organ damage. These factors are glycosylation of tissue proteins, intracellular accumulation of sorbitol and oxidative stress (4). The association between the consumption of beverages sweetened with sugars such as HFCS and the risk of diabetes has been established by Schultze et al (20).

From our study, it seems that fructose is not the only risk factor of liver disease, because $40 \%$ of our cohort were drinking Diet Coke sweetened with aspartame. Aspartame is absorbed from the intestine and metabolized by the liver to form phenylalanine, aspartic acid and methanol. This process causes mitochondrial dysfunction and ATP depletion, which contribute to accumulation of fat (29). Also, regarding obesity and aspartame, formaldehyde converted from the free methyl alcohol accumulates in the cells and damages mitochondrial DNA, with most toxicity effects occurring in the liver. Finally, the effect of caramel colourant has been incriminated as a cause of elevated liver enzymes and may be a potential source of advanced glycation end product, which may promote insulin resistance and can be proinflammatory $(5,6,20)$. The extent to which fructose, aspartame and caramel contributed to severe fatty liver could not be concluded due to the small size of the cohort.

When controlled for other factors, including dietary composition and physical activity, soft drink beverage consumption was the only independent variable that could correctly classify the presence of fatty infiltration of the liver. A study by Vartanian et al (30) showed a clear association among soft drink intake, diabetes and the metabolic syndrome, confirming our finding. Although we still do not know the most common soft drink that induces fatty liver, fructose, caramel and aspartame constituents may have a role. These coingestants might also increase the risk for fatty liver because of their high amount of rapidly absorbable carbohydrates (20). They contain a large amount of HFCS, which has a similar effect on blood glucose as sucrose (31). The consumption of sugarsweetened soft drinks therefore induces a fast and dramatic increase in both glucose and insulin concentration (32). In addition, cola-type soft drink caramel colouring is rich in advanced glycation end products, which may increase insulin resistance and inflammation (6,33). The US Food and Drug Administration has established $51 \mathrm{mg}$ of aspartame and $200 \mathrm{mg}$ of caramel colouring per $\mathrm{kg}$ body weight as an acceptable daily intake. The natural history of NAFLD is not known. The present study may add important insight into the role of sugar-sweetened beverage consumption as a cause of fatty

\section{REFERENCES}

1. Angulo P. Nonalcoholic fatty liver disease. N Engl J Med 2002;346:1221-31.

2. Assy N, Kaita K, Mymin D, Levy C, Rosser B, Minuk G. Fatty infiltration of liver in hyperlipidemic patients. Dig Dis Sci 2000;45:1929-34.

3. Burke A, Lucey MR. Non-alcoholic fatty liver disease, non-alcoholic steatohepatitis and orthotropic liver transplantation. Am J Transplant 2004:4:686-93.

4. Gaby AR. Adverse effects of dietary fructose. Altern Med Rev 2005; 10:294-306.

5. Vlassara H, Cai W, Crandall J, et al. Inflammatory mediators are induced by dietary glycotoxins, a major risk factor for diabetic angiopathy. Proc Nat Acad Sci U S A 2002;99:15596-601. (Erratum in 2003;100:763).

6. Hofmann SM, Dong HJ, Li Z, et al. Improved insulin sensitivity is associated with restricted intake of dietary glycoxidation products in the $\mathrm{db} / \mathrm{db}$ mouse. Diabetes 2002;51:2082-9. liver in those without risk factors. The time from NAFLD diagnosis to enrolment in the study was less than two weeks. Therefore, the information obtained for dietary food consumption was a good reflection of the patient's dietary habits before the diagnosis of NAFLD.

Some limitations merit further comment. The first limitation is the use of ultrasound to assess liver fat content. However, the sensitivity (92\%) and specificity (100\%) of ultrasound to show increased fatty infiltration are very good, and its accuracy approaches $100 \%$ for patients with moderate to severe steatosis (34). The second limitation is that other covariants present in the food or some dietary habits (eg, drinking carbonated beverages facilitates the intake of fatty food such as pizza) may have played a role in the observed relationship between soft drink beverages and hepatic steatosis. Third, the number of patients and controls was small for a study relating to dietary habits in which variability and errors are possible. A much larger patient group with a stronger power to look for unmeasured confounding variables or bias by control selection is needed. Finally, dietary and physical activity information was obtained through self-reported questionnaires, which may be subject to underreporting and interviewer bias. However, these questionnaires were validated and were appropriate in capturing their usual dietary intake. In addition, the dietary collection was for two seven-day records (at the beginning and the end of the study period), yet the results were extrapolated over 36 months. This has been validated by Pisani et al (35). The rationale behind this is compliance, ethnic background and the sociocultural homogeneity of the population studied. Traditional habits in cooking practices are quite similar throughout the region and tend to persist in their descendents. The findings of the present study should not be directly extrapolated to 'general NAFLD patients' because we compared soft drink consumption in an atypical group of NAFLD patients (ie, no classic risk factors, $10 \%$ of the general population).

\section{CONCLUSIONS}

Although more studies are needed, the findings of the present study suggest that soft drink consumption is the most common risk factor for fatty infiltration of the liver in patients without classic risk factors. Patients are encouraged to change their longstanding drinking behaviour. Whether consumption of soft drinks contributes to the progression of simple fatty liver to steatohepatitis in patients with metabolic syndrome is yet to be determined.

7. Toshimitsu K, Matsuura B, Ohkubo I, et al. Dietary habits and nutrient intake in non-alcoholic steatohepatitis. Nutrition 2007;23:46-52.

8. Davail S, Rideau N, Bernadet MD, Andre JM, Guy G, Hoo-Paris R. Effects of dietary fructose on liver steatosis in overfed mule ducks. Horm Metab Res 2005;37:32-5.

9. Kelly GL, Allan G, Azhar S. Higher dietary fructose induces a hepatic stress response resulting in cholesterol and lipid dysregulation. Endocrinology 2004;145:548-55.

10. Santer R, Rischewski J, von Weihe M, et al. The spectrum of aldolase $B(A L D O B)$ mutations and the prevalence of hereditary fructose intolerance in Central Europe. Hum Mutat 2005;25:594

11. Dhingra R, Sullivan L, Jacques PF, et al. Soft drink consumption and risk of developing cardiometabolic risk factors and the metabolic syndrome in middle-aged adults in the community. Circulation 2007;116:480-8. (Erratum in 2007;116:e557). 
12. Block G, Woods M, Potosky A, Clifford C. Validation of a selfadministered diet history questionnaire using multiple diet records. J Clin Epidemiol 1990;43:1327-35.

13. Paffenbarger RS Jr, Wing AL, Hyde RT. Physical activity as an index of heart attack risk in college alumni. Am J Epidemiol 1978;108:161-75.

14. Giovannucci E, Colditz G, Stampfer MJ, et al. The assessment of alcohol consumption by a simple self-administered questionnaire. Am J Epidemiol 1991;133:810-7.

15. Scatarige JC, Scott WE, Donovan PJ, Siegelman SS, Sanders RC. Fatty infiltration of the liver: Ultrasonographic and computed tomographic correlation. J Ultrasound Med 1984;3:9-14.

16. Saverymuttu SH, Joseph AE, Maxwell JD. Ultrasound scanning in the detection of hepatic fibrosis and steatosis. Br Med J (Clin Res Ed) 1986;292:13-5.

17. Ludwig DS, Peterson KE, Gortmaker SL. Relation between consumption of sugar-sweetened drinks and childhood obesity: A prospective, observational analysis. Lancet 2001;357:505-8.

18. Popkin BM, Armstrong LE, Bray GM, Caballero B, Frei B, Willett WC. A new proposed guidance system for beverage consumption in the United States. Am J Clin Nutr 2006;83:529-42.

19. Nandhini AT, Balakrishnan SD, Anuradha CV. Response of liver antioxidant system to taurine in rats fed high fructose diet. Indian J Exp Biol 2002;40:1016-9.

20. Schulze MB, Manson JE, Ludwig DS, et al. Sugar-sweetened beverages, weight gain, and incidence of type 2 diabetes in young and middle-aged women. JAMA 2004;292:927-34

21. McDevitt RM, Bott SJ, Harding M, Coward WA, Bluck LJ, Prentice AM. De novo lipogenesis during controlled overfeeding with sucrose or glucose in lean and obese women. Am J Clin Nutr 2001;74:737-46.

22. Teff KL, Elliott SS, Tschop M, et al. Dietary fructose reduces circulating insulin and leptin, attenuates postprandial suppression of ghrelin, and increases triglycerides in women. J Clin Endocrinol Metab 2004;89:2963-72.

23. Porikos KP, Van Itallie TB. Diet-induced changes in serum transaminase and triglyceride levels in healthy adult men. Role of sucrose and excess calories. Am J Med 1983;75:624-30.
24. Oberhaensli RD, Galloway GJ, Taylor DJ, Bore PJ, Radda GK. Assessment of human liver metabolism by phosphorus-31 magnetic resonance spectroscopy. Br J Radiol 1986;59:695-9.

25. Simko V. Increase in serum lipids on feeding sucrose: The role of fructose and glucose. Am J Clin Nutr 1980;33:2217.

26. Hallfrisch J, Reiser S, Prather ES. Blood lipid distribution of hyperinsulinemic men consuming three levels of fructose. Am J Clin Nutr 1983;37:740-8.

27. Vuilleumier S. Worldwide production of high-fructose syrup and crystalline fructose. Am J Clin Nutr 1993;58(5 Suppl):733S-36S

28. Michal G, ed. Biochemical Pathways: An Atlas of Biochemistry and Molecular Biology, Whily: John Wiley and Sons, 1999:27.

29. Trocho C, Pardo R, Rafecas I, et al. Formaldehyde derived from dietary aspartame binds to tissue components in vivo. Life Sci 1998;63:337-49.

30. Vartanian LR, Schwartz MB, Brownell KD. Effects of soft drink consumption on nutrition and health: A systematic review and meta-analysis. Am J Public Health 2007;97:667-75.

31. Akgun S, Ertel NH. The effects of sucrose, fructose, and high-fructose corn syrup meals on plasma glucose and insulin in non-insulin-dependent diabetes subjects. Diabetes Care 1985;8:279-83.

32. Janssens JP, Shapira N, Debeuf P, et al. Effects of soft drink and table beer consumption on insulin response in normal teenagers and carbohydrate drink in youngsters. Eur J Cancer Prev 1999;8:289-95.

33. Yoshida M, McKeown NM, Rogers G, et al. Surrogate markers of insulin resistance are associated with consumption of sugar-sweetened drinks and fruit juice in middle and older-aged adults. J Nutr 2007;137:2121-7.

34. Hamaguchi M, Kojima T, Itoh Y, et al. The severity of ultrasonographic findings in nonalcoholic fatty liver disease reflects the metabolic syndrome and visceral fat accumulation. Am J Gastroenterol 2007;102:2708-15.

35. Pisani P, Faggiano F, Krogh V, Palli D, Vineis P, Berrino F. Relative validity and reproducibility of a food frequency dietary questionnaire for use in the Italian EPIC centres. Int J Epidemiol 1997;26(Suppl 1):S152-60. 


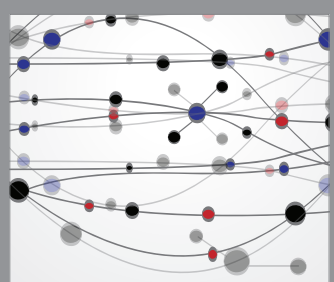

The Scientific World Journal
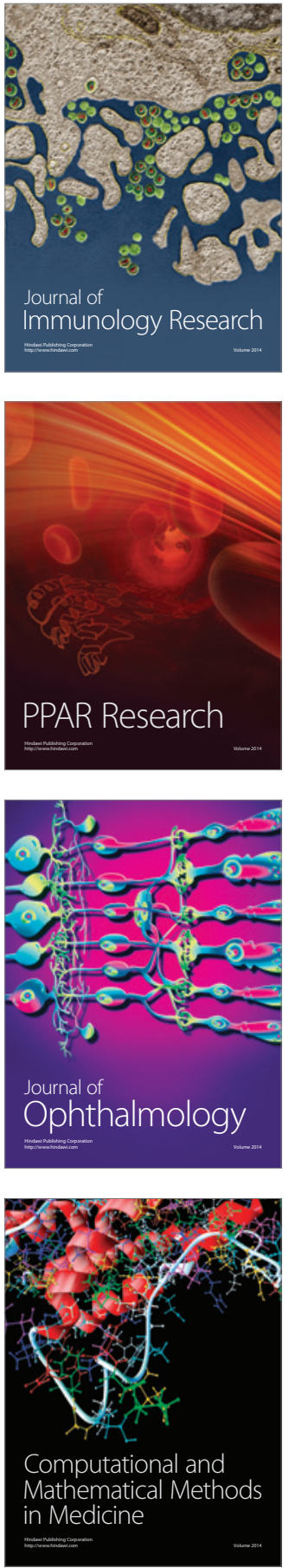

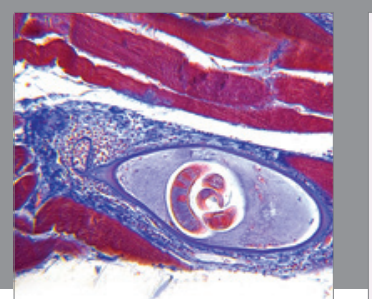

Gastroenterology Research and Practice

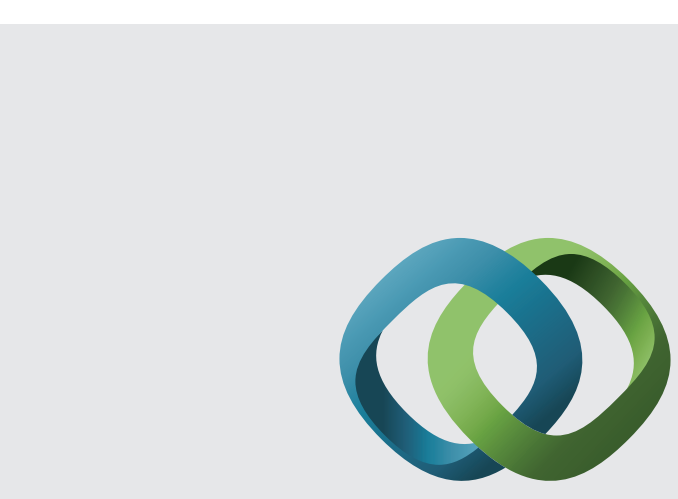

\section{Hindawi}

Submit your manuscripts at

http://www.hindawi.com
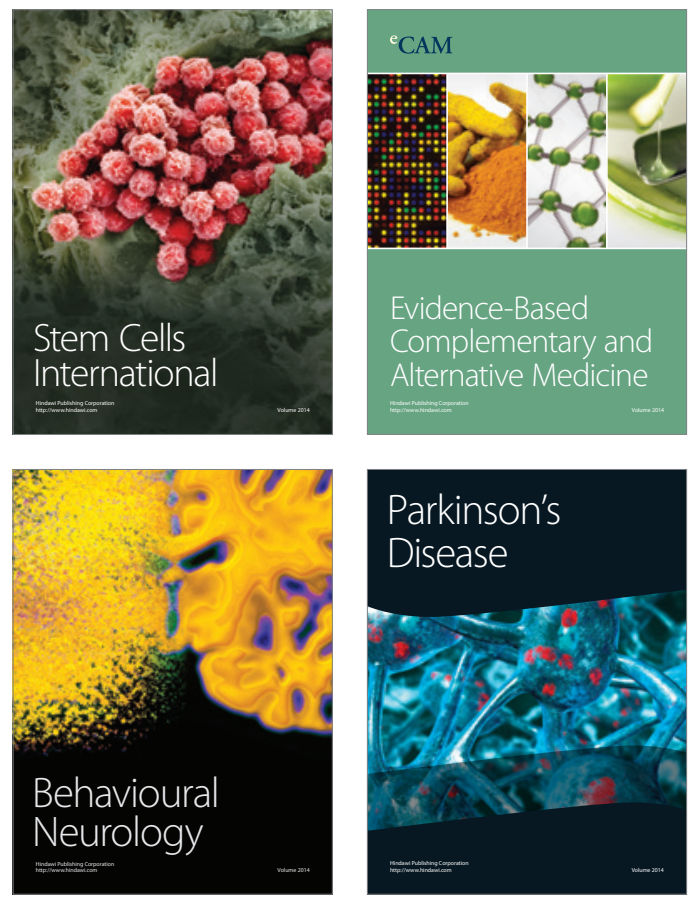
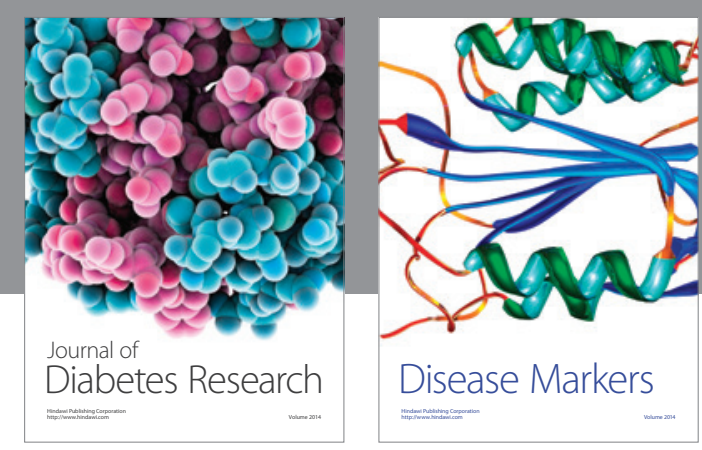

Disease Markers
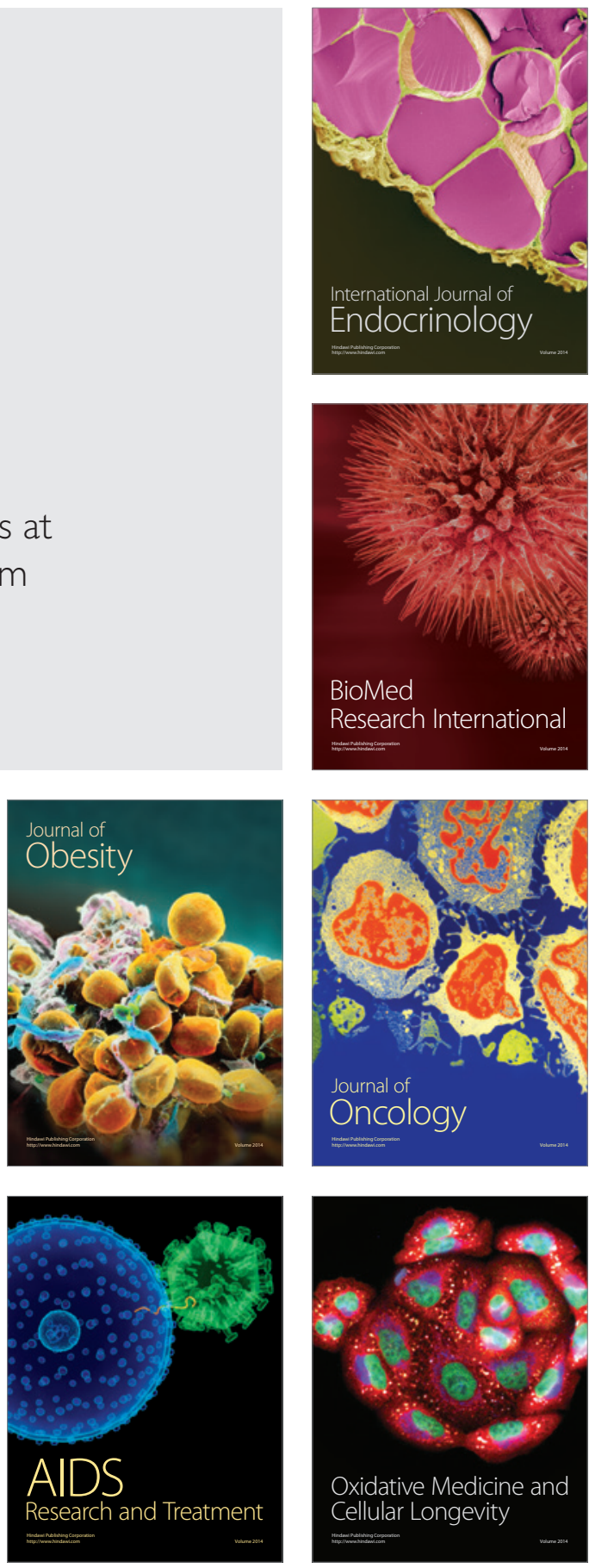